\title{
COVID-19 Pandemic and Tourism: A Risk Management Analysis of Iran
}

\author{
Jamileh Ghasemloi-Soltanabad \\ Management Department, Humanities Faculty, Science and Arts University, Iran. \\ j.ghasemloi1@gmail.com
}

Mirmohamad Asadi

Management Department, Humanities Faculty, Science and Arts University, Iran. asadi@sau.ac.ir

Maryam Ahmadi-Salman

Humanities Faculty, Islamic Azad University North Tehran Branch, Iran

M.ahmadis@yahoo.com

\begin{abstract}
Purpose: Tourism that inherently has human interaction and mobility is more at risk than any other industry. Because of its highly competitive nature, tourism has to be prepared to deal with problems.
\end{abstract}

Study design/methodology/approach: In this developmental-applied study, the researchers tried to consider the extent of the COVID-19 pandemic as a global crisis by the Fuzzy Cognitive Mapping technique (FCM).

Findings: According to the findings, confidence-building propaganda action plan, tax forgiveness, and payment of subsidies and support, the need to take knowledge of crisis management seriously, forming a crisis management team, and target market design are the most important strategies for overcoming the corona crisis.

Originality/value: The present study's findings may have significant theoretical and practical implications for risk management students and experts.

Keywords: COVID-19, Crisis Pathology, Tourism Risk Management, Fuzzy Cognitive Mapping Technique (FCM)

\section{Introduction}

Epidemics and pandemics as public health-related crises can have a variety of negative impacts on tourism because travelling can facilitate the spread of infectious diseases (Mason, Grabowski, \& Du, 2005). According to World Health Organization (WHO), a pandemic is the worldwide spread of a new disease. In fact, a pandemic can be an "extensively epidemic" (Stedman's medical dictionary, 2006) and "epidemic over a very wide area usually affecting a large proportion of the population" (Last JM, 1988, 94). WHO has recommended a series of travel restrictions for countries experiencing coronavirus outbreaks. These restrictions have been applied to a diversity of affairs in many countries, which has significantly affected tourism (WHO \& UNWTO, 2020).

Over the past fifteen years, many health-related crises, especially epidemics and pandemics such as SARS and Ebola, as well as Foot and Mouth disease, have severely damaged the tourism industry at the regional and international levels (see Frisby, 2003; Novelli, Gussing-Burgess, Jones, \& Ritchie, 2018; Zeng, Carter, \& De-Lacy, 2005). The standard definition of tourism by Hunziker (1951) states that tourism is a group of relations and phenomena that result from the travels and sojourns of visiting persons, as far as settlement and subsequent use does not take place. As a social-sensitive and event-related industry that inherently has human interaction and mobility, tourism is riskier than any other industry. However, because of its highly competitive nature, the activists of this industry should be ready to deal with problems and challenges.

\section{Literature Review}


"Pandemic" has never been a scientific term but rather a popular subjective term. Since the mid1600 s, the word pandemic, or pandemick, was at first very imprecise that it could mean different, even contradictory, things in different contexts (see Morens, Folkers \& Fauci, 2009). At its most specific, it conveyed the vague notion of an impressively large epidemic, and its Greek roots, pan (i.e., all) and demos (i.e., people) reflect its widespread nature. The epidemic is often translated from the Greek as "that which is upon the people", i.e., a high-incidence or widely prevalent condition. It is most frequently employed when there is rapid temporal and geographical spread.

The COVID-19 pandemic as a crisis of the tourism industry from 2019 on requires risk and crisis management. Crisis management involves coordinating complex technical and relational systems and designing organisational structures to prevent the occurrence, reduce the impact, and learn from a crisis (Coombs, 2007; Bundy \& Pfarrer, 2015). Therefore, in the following paragraphs, it is necessary to analytically review some pieces of recent research done on the impacts of the COVID-19 on the tourism industry.

Gössling, Scott and Hall (2020), in their paper entitled "Pandemics, tourism and global change: a rapid assessment of the COVID-19", compared the impacts of the COVID-19 to previous epidemic/pandemics and other types of global crises and explores how the pandemic may change society, the economy, and tourism. According to their findings, the COVID-19 provides striking lessons to the tourism industry, policymakers, and tourism researchers about the effects of global change.

Jiang and Wen (2020), in "Effects of the COVID-19 on hotel marketing and management: A perspective article", discuss the possible effects of the COVID-19 pandemic on hotel marketing and management practices and how hoteliers may respond to such challenges to recover after this pandemic. They present research agenda from three dimensions - artificial intelligence (AI) and robotics, hygiene and cleanliness, and health and healthcare. First, different types of AI (mechanical, thinking, and feeling) might open up distinct research streams at the intersection of health crises and hotel management in light of the COVID-19 pandemic. In addition, they recommend that researchers move beyond typical perspectives on the antecedents and outcomes of hotel hygiene and cleanliness to delve into guests' perceptions of the cleanliness of specific hotel surfaces.

Alzoubi and Jaaffar (2020), in an essay "Leadership styles, crisis management, and hotel performance: a conceptual perspective of the Jordanian hotel industry", suggested reviewing the literature to develop a conceptual framework addressing the role of crisis management in leadership and hotel performance. They proposed a holistic conceptual framework that incorporates the intermediary role of crisis management to achieve optimal hotel performance. Accordingly, the results of their study will provide insights into the role of crisis management by informing leaders. In addition, the results will provide empirical evidence on the effectiveness of crisis management in improving hotel performance during a crisis.

Goletsa, Fariasb, Pilatib and Costa (2020), in their article entitled "the COVID-19 pandemic and tourism: The impact of health risk perception and intolerance of uncertainty on travel intentions", evaluate travel intentions of Brazilians during the COVID-19 pandemic. Their findings have implications for tourism practitioners and authorities because they can track travellers' personal data, thereby helping the destination recover faster.

Yeh (2020), in his article "Tourism recovery strategy against the COVID-19 pandemic", highlight it is vital to have well thought out tourism crisis and disaster management (TCDM) to mitigate the impact and help with post-crisis recovery. Their study uses a qualitative research method to examine the TCDM during the current crisis. The results indicate that open communication is a key to combat pandemics successfully, and government-sponsored loans 
are crucial to the survival of the tourism industry. Thus, government plays a significant role in the fight against the COVID-19 on many levels, such as the economy's recovery that includes the tourism industry.

Davahli, Karwowski, Sonmez and Apostolopoulos (2020), in their paper "The Hospitality Industry in the Face of the COVID-19 Pandemic: Current Topics and Research Methods", reported on a systematic review of the published literature used to reveal the current research investigating the hospitality industry in the face of the COVID-19 pandemic.

Zielinski and Botero (2020), in their article "Beach Tourism in Times of the COVID-19 Pandemic: Critical Issues, Knowledge Gaps and Research Opportunities", discuss that the economic importance of beach tourism for many destinations has led many governments to reopen tourist beaches, as soon as the number of infection cases decreased. Furthermore, they try to provide a scientific basis for understanding the critical issues for beach tourism management in these circumstances. These issues include risk perception, environmental considerations directly related to beaches and the COVID-19, and management strategies designed to limit the risk of contagion on the beach.

Madani, Boutebal, Benhamida, and Bryant (2020), in their article "The Impact of the COVID19 Outbreak on the Tourism Needs of the Algerian Population", aimed to understand the vision and the reaction of the population towards tourism and holidays during this period of the COVID-19 pandemic. The results showed a great need for recreation sustainability and relaxation to relieve psychological stress that has caused adverse effects on the physical and mental health of all people, including children, during the COVID-19 period.

The present researchers did their best to investigate the tourism-related challenges and problems in the COVID-19 era and tourism opportunities and executive strategies. To achieve the objectives of the present study, the following research questions were posed:

RQ1. What are the possible challenges of the international tourism industry in the COVID19 era?

RQ2. What are the tourism opportunities in the post-Covid19 era?

RQ3. What are the executive strategies for resilience and exit from the COVID-19 era?

\section{Method}

Using the reports of domestic and international organisations, interviews were conducted with 9 experts from the university community, industry tourism, and the Ministry of Cultural Heritage and Tourism' experts to address the research topic. For demographic information of the selected participants, see Table 1 .

Table 1: Demographic Information of the Participants

\begin{tabular}{|l|l|l|l|l|}
\hline Interviewee & Sex & Age & Education & Position and Background \\
\hline Number 1 & Male & $54-60$ & PhD. & $\begin{array}{l}\text { University professor, more than 7 years of teaching related to } \\
\text { tourism }\end{array}$ \\
\hline Number2 & Male & $46-54$ & M.A & $\begin{array}{l}\text { A hotel industry expert with more than 5 years of } \\
\text { management experience }\end{array}$ \\
\hline Number 4 & Male & $46-54$ & PhD. & $\begin{array}{l}\text { A transport industry expert with more than 7 years of } \\
\text { supervision and management experience }\end{array}$ \\
\hline Number 5 & Female & $54-60$ & M.A & $\begin{array}{l}\text { Expert of the Ministry of Cultural Heritage and Tourism with } \\
\text { supervision and management experience } \\
\text { more than 7 years of supervision and management experience }\end{array}$ \\
\hline Number 6 & Male & $54-60$ & PhD. & $\begin{array}{l}\text { Representative of Hotel and Transport Holding with more } \\
\text { than 7 years of experience in supervision }\end{array}$ \\
\hline
\end{tabular}




\begin{tabular}{|l|l|l|l|l|}
\hline Number 7 & Female & $46-54$ & M.A & $\begin{array}{l}\text { Expert in travel service offices with more than 5 years of } \\
\text { experience in supervision }\end{array}$ \\
\hline Number 8 & Male & $46-54$ & PhD. & $\begin{array}{l}\text { Expert of the Ministry of Cultural Heritage and Tourism with } \\
\text { more than 5 years of experience in supervision }\end{array}$ \\
\hline Number 9 & Male & $54-60$ & PhD. & $\begin{array}{l}\text { Representative of travel Agencies with more than 7 years of } \\
\text { supervision and management experience }\end{array}$ \\
\hline
\end{tabular}

This paper utilised the qualitative method and interview as data collection instrumentation to achieve the study's objectives and answer the research questions. Qualitative research deals with its meaning instead of measuring and evaluating the phenomenon of the organisation. The qualitative research assumes that organisational reality is unclear and uncertain, but projecting human imagination is. Those who prefer qualitative research state that to discover new knowledge, direct intervention in organisations and the use of human emotions to interpret the phenomenon of an organisation is essential (see Daft, 1983). Interviewing is undoubtedly one of the most widely used techniques for conducting systematic social research. Sociologists, psychologists, anthropologists, psychiatrists, bureaucrats, politicians, and election observers view interviews as "windows to the world" (see Kvale, 1996). The reason for choosing the interview as a data collection method was to collect current research information, that is, the lack of previous field research on epidemic experiences on a global scale. In addition, the Fuzzy cognitive mapping technique (FCM) was used to analyse the data obtained from the interviews.

\section{Data Analysis and Findings}

In this section, first, the research questions of the present study will be answered separately. Then, based on the obtained data, Fuzzy Cognitive Mapping (FCM) technology was proposed.

\subsection{Challenges of Tourism Industry in the COVID-19 era}

A semi-structured interview was prepared and run to answer the first research question on identifying the challenges of the tourism industry in the COVID-19 period. According to the data obtained from interviews, as you see in Table 2 (s also shown in Table 6), 12 cases are presented as the challenges of the tourism industry in the COVID-19 era.

Table 2: Challenges of Tourism industries in the Face of the COVID-19 Outbreak Crisis

\begin{tabular}{|l|l|}
\hline Number & Challenges \\
\hline 1 & Pay staff salaries \\
\hline 2 & Bank instalments payments, rent, bills, taxes and staff insurance premiums paying \\
\hline 3 & $\begin{array}{l}\text { Refund of cancelled travel funds (impossibility of refunding paid funds for booking foreign } \\
\text { payments and hotels) }\end{array}$ \\
\hline 5 & Trained manpower layoffs \\
\hline 6 & Hotels upkeep costs at the time of hotel closure \\
\hline 7 & The health and safety of staff and tourists' matter \\
\hline 8 & Prolonged epidemic and passenger intolerance \\
\hline 9 & The extent of the consequences of this incident (epidemic) \\
\hline 10 & Fear of the future \\
\hline 11 & The departure of service offices from a normal situation \\
\hline 12 & Lack of perspective and clear picture of the future \\
\hline
\end{tabular}

In Table 3, obtained from the data obtained from interviews, 15 challenges in the public sector of Iran were analytically addressed.

Table 3: Challenges of the Public Sector in Dealing with the Crisis of the Outbreak of the COVID-19 in Tourism

\begin{tabular}{|l|l|}
\hline Number & \multicolumn{1}{c|}{ Challenges } \\
\hline 1 & The unemployment rate in crescent in the country as a result of the closure of tourism activities \\
\hline 2 & Lack of government funding to support affected businesses \\
\hline
\end{tabular}




\begin{tabular}{|l|l|}
\hline 3 & Lack of efficient risk management system \\
\hline 4 & Conflict resolution management among tourism stakeholders \\
\hline 5 & Ensuring the health and safety of passengers \\
\hline 6 & Establishing health protocols for tourism facilities \\
\hline 7 & Typology of the Corona crisis \\
\hline 8 & Personnel training in the tourism sector \\
\hline 9 & The lack of tourism industry support funds \\
\hline 10 & Concerns about political and social tensions following the deepening of economic challenge \\
\hline 11 & Stress on people \\
\hline 12 & lack of clear regulations in the country and lack of crisis subjects explicitly \\
\hline 13 & The challenge of socio-cultural development and family happiness in crisis situations \\
\hline 14 & Lack of rules for costs compensation \\
\hline 15 & Responsibility towards the public and private sector \\
\hline
\end{tabular}

\subsection{Tourism Opportunities in Post-COVID-19 Era}

To find opportunities to compensate for the consequences of the crisis, adapt to the current difficult situation, and answer the second question of the research, the interview was continued.

Six of 9 interviewees referred to the crisis as "a flip to the tourism sector", noting that instead of focusing most of their efforts on maximising customers and increasing profits and expanding their operations, they should tend to focus on stabilising tourism activities, necessary for them to continue their lives. One of the interviewees said: "Tourism is an industry that is very vulnerable to various crises, but the dimensions of the corona are its epidemic and its duration, and its typology is important for risk assessment". It is possible by transforming the traditional tourism model into a new model based on tourists' needs and the sustainability of tourism goods. Such a system prioritises the safety and security of the tourist. Studying past crises and adopting strategies to minimise the damage caused by them can support the tourism industry in the ups and downs and crises ahead.

Five of the nine experts noted that by increasing digital marketing and connecting with their audience at home and abroad, they could be assured that they will do their utmost to travel safely and without risk. One of the interviewees pointed out, "The pandemic or corona epidemic debate has affected tourism and transportation. Risk management is about safety or passenger safety; it is about the safety and health of tourists and staff". Something else that can be mentioned is that those working in the country's tourism sector, such as transportation and accommodation, must continue to maintain contact with their former customers in various ways, despite the outbreak of the corona epidemic and tourists' requests reduction. This will keep customers who are currently unable to travel.

Four experts pointed out the need to control fixed and indirect costs and that costs should be controlled and reduced or compensated in various ways. For example, one of the interviewees believed, "In case of hotel closure, the cost of maintaining the hotel is more than when the hotel is open. There are 80,000 direct employees in hotels that are virtually unemployed". Obviously, small businesses have less ability to deal with unforeseen crises than larger competitors do. Still, at the same time, there is a higher chance of lower costs and more flexibility in changing strategies.

Paying attention to the assets, credits, and relationships between the tourism industry and others is another opportunity that five experts paid attention to. Work experience and international relations are the assets of travel companies. These companies have many customers in the country of origin and have a good memory of the destination country; therefore, they are headquartered in the country of origin. One of the interviewees asserted, "Each of the tourism parts, such as rosary beads, are associated with travel services offices and are affected by the 
current situation. For example, the Corona epidemic occurred at a time when travel was at its peak, and revenue streams were seeking compensation after floods and plane crashes in the fall of 2019, in which the entire chain collapsed and travels were stopped. More than 4,000 travel services offices across the country operate in the field of domestic, inbound, and outbound travel, and all were in trouble. In this case, we faced the lack of rules and regulations needed to deal with this situation". Convenience companies or travel agencies that work in attracting foreign customers. Having learned about international marketing methods, this capability can be used in the tourism industry.

Four interviews pointed to the lack of accurate information and statistics from various sectors of tourism, especially the extraction of statistics and assessment of conditions at the local level, to provide a coherent and evaluated response to the crisis. To create this opportunity and reduce the adverse effects of coronavirus outbreaks, it is essential to provide travellers with up-to-date and accurate information about the current state of the epidemic, how to protect themselves and others in an outbreak, and identify high-risk areas. Providing such data requires a partnership between the tourism sector and the country's health sector. Another point mentioned by five interviewees is to create a sense of commitment and responsibility in and among the tourists to maintain their health and the individuals with whom they travel.

Six experts pointed to the opportunity to understand the behaviour and demands of the business, maintaining and caring for the work team and workforce, which is one of the first actions of companies in difficult conditions, and reducing costs and workforce. Of course, it is also important to note that building a new team is hard work and slows down the growth process after the crisis. It is necessary to maintain a trained and experienced workforce and to continue to work and encourage initiative and innovation at work. Despite all the challenges, business owners still need to be more patient and seize this period as a long-term opportunity.

Five of the interviewees mentioned the need to pay attention to the value of the country's currency compared to the common currencies for planning the attraction of foreign tourists and development in the post-COVID-19 as a necessary saviour and opportunity for businesses.

Six experts considered the necessity of unity, solidarity, creating more interaction, and forming think-tanks. They believe that continuously using the opinions of associations and pioneers of the private sector to make decisions and measures the necessary precondition for this period and forming a working group of tourism activists to identify common concerns and find a solution and pursue answers is a big step in this phase. Furthermore, experience has shown that guilds will have considerable power to follow their trade union rights if they reach a common language and speech. According to the challenges ahead in the tourism industry based on the data obtained from the interviewees, Table 4 lists the leading opportunities in the tourism business.

Table 4: Summarising the Opportunities

\begin{tabular}{|l|l|}
\hline Number & Opportunities \\
\hline 1 & $\begin{array}{l}\text { Transforming the traditional model of tourism into a new model based on the needs of tourists and } \\
\text { the stability of services and goods in crisis }\end{array}$ \\
\hline 2 & $\begin{array}{l}\text { Increasing digital marketing and communication with domestic and foreign audiences to build a } \\
\text { safe travel destination }\end{array}$ \\
\hline 3 & $\begin{array}{l}\text { Maintaining and communicating with previous and loyal customers as starting points (i.e., travel } \\
\text { initiator })\end{array}$ \\
\hline 5 & Small businesses through cost control and flexibility to change strategies \\
\hline 6 & $\begin{array}{l}\text { Creating parallel and complementary businesses to reduce vulnerabilities in crises } \\
\text { tourism sector and the health sector of the country }\end{array}$ \\
\hline 7 & $\begin{array}{l}\text { Low price of the country's currency, the opportunity to plan the attraction of foreign tourists by } \\
\text { observing health protocols }\end{array}$ \\
\hline
\end{tabular}




\begin{tabular}{|l|l|}
\hline 8 & $\begin{array}{l}\text { Interacting with tourism associations and tourism pioneers by forming a think tank and exchanging } \\
\text { views, and pursuing trade union rights }\end{array}$ \\
\hline 9 & $\begin{array}{l}\text { Stimulating the tourists' sense of commitment and responsibility to maintain the health of } \\
\text { themselves and other fellow travellers }\end{array}$ \\
\hline 10 & $\begin{array}{l}\text { Understanding the behaviour and desires of businesses, caring for and maintaining the work team } \\
\text { and manpower }\end{array}$ \\
\hline
\end{tabular}

\subsection{Executive Strategies for Resilience and Exit from the COVID-19 Era}

After questions and answers about the challenges and opportunities, it was time to address the recommendations. Six experts pointed out the need to take crisis management knowledge and job resilience seriously in tourism businesses and considered it necessary to pay more attention to upstream factors such as government, policymakers, and planners, and to collect and summarise information and solutions by people at the regional level. In addition, locally active are highlighted. Controlling and keeping fixed costs low is critical for tourism companies. In fact, more strict cost control makes companies more agile and allows them to overcome crises and withstand further fluctuations. Changes in the marketing environment force organisations to develop strategy agility before, during, and after the COVID-19 epidemic (He \& Harris, 2020). Resources and capabilities in the field of development-related activities, seven of the interviewees stated that we need to consider the tourism industry, volatile and high-risk. It may be better for active groups in this industry to create a safe area for themselves and, in addition to the usual tourism activities, to take side measures in the target markets. This allows them to move in a safe zone with various shocks and stresses, ensure the cash flow to some extent, and increase the company's resilience to accidents. Therefore, businesses must now look to expand their capabilities and be able to operate in one or two related areas at the same time. Sometimes even unrelated areas can be effective. In the past, organisations had hidden and potential entrepreneurial and innovative sources that witnessed the triumph of creativity and pure rationality over incompatibility (see Armstrong, 2020). Setting up small but professional teams, such as a professional team of advertising,well-thought-out idea processors and content producers, online services, recognising international competitors and market psychology, audience and customer attraction, intra-organizational problem-solving and presenting it for correction, market identification and internal and external marketing, communications and negotiations, and small specialised teams can be among essential tools for progress.

In the areas of management, recruitment and business expansion, and considering the challenges and opportunities ahead in the post-COVID-19 era, eight experts refer to the following. Forming a risk management team including financial, marketing, executive, legal, and public relations managers, using defensive strategies such as partnerships, reducing parts of the organisation, conducting marketing management processes, as well as reviewing marketing processes, identifying the needs of tourists, the target community in the package of providing advice to tourists, and providing travel offers individually or as a family. The use of sales promotion strategies and advertising processes should also be in a way that expresses social responsibility in crisis and creates an atmosphere of trust and confidence to maintain the safety and health of tourists. This epidemic teaches us that we are all together and undoubtedly increases individuals' expectations of jobs for social responsibility (He \& Harris, 2020).

Seven experts highlighted the payment of subsidies and the allocation of low-cost facilities, exemption of taxes and energy bills for tourism industry activists by the government. They suggested strengthening infrastructures to enter into the network and use websites, platforms and social media. According to the value of Iran's currency compared to the common currencies, they were introduced as an important saviour and opportunity for businesses to plan for attracting foreign tourists and developing in the post-COVID-19 era. Naturally, professional 
translation of services into the world's living languages is the way to communicate with foreign tourists after Corona.

However, in the tourism industry, along with controlling and reducing the disease at the community level, four experts emphasised that in the scenario writing sector, in the COVID-19 era, we do not start from the domestic or foreign sector because the discussion of travel is no longer a priority in the household basket. It does not count; there is a need, though. Due to the outbreak of coronavirus and lack of well-controlled countries, alternative tourist destinations with a white flag (with the white flag, i.e., less infected with coronavirus) are prioritised. Therefore, the white flag cities are in demand by future tourists. For this purpose, it is possible to implement the plan to determine the target market at the international and domestic level, present a plan to separate the target countries, present a plan to adapt the market and adapt and simulate products and services they demand of tourists. After the spread of the disease in the target countries, the presentation of the action plan promoted confidence-building measures for the safety and security of tourists in the country (see Bulletin Number 8, 2020). According to identified opportunities in tourism and points of emphasis in the interviews, the strategies or solutions for the tourism industry are presented in Table 5.

Table 5: Strategies in the Tourism industry

\begin{tabular}{|l|l|}
\hline Number & Solutions \\
\hline 1 & Stimulating the sense of responsibility in the tourist to maintain the health of herself and others \\
\hline 2 & Providing a plan to adapt the market and simulate products to the demand of tourists \\
\hline 3 & $\begin{array}{l}\text { Maintaining and communicating with previous and loyal customers as starting points (travel } \\
\text { initiator) }\end{array}$ \\
\hline 4 & Starting small but professional teams \\
\hline 5 & $\begin{array}{l}\text { Maintaining and communicating with previous and loyal customers as starting points (i.e., travel } \\
\text { initiator) }\end{array}$ \\
\hline 6 & $\begin{array}{l}\text { Exemption of business taxes and energy bills for tourism industry activists and payment of } \\
\text { government subsidies and support }\end{array}$ \\
\hline 8 & $\begin{array}{l}\text { The low price of the country's currency is an opportunity to plan the attraction of foreign tourists } \\
\text { in accordance with health protocols }\end{array}$ \\
\hline 9 & Providing an action plan in the target countries \\
\hline 10 & Recognising the behaviour and desires of businesses \\
\hline 11 & Collecting and summarising information at the regional and local level \\
\hline 12 & $\begin{array}{l}\text { Implementing the target market determination plan at the international level and identification of } \\
\text { target countries and cities (with the white flag, i.e., less infected with coronavirus) }\end{array}$ \\
\hline 13 & Presenting an action plan to build trust in the safety and security of tourists in the country \\
\hline 14 & Forming a crisis management team \\
\hline 15 & Control of fixed and overhead costs for organisational agility \\
\hline
\end{tabular}

\subsection{Fuzzy Cognitive Mapping Technique}

The fuzzy Cognitive Mapping Technique (FCM) associates facts, objects, and processes with values, policies, and goals. This soft computational method for modelling systems predicts interactions, how complex events work, and answers meaningful questions (See, Jose, 2009). With the help of FCM, an overview of the relationships among success factors is presented, and the impact of CSFs on the organisation's goals is evaluated. Perceptual mapping, graphic contains two main elements of concepts and causal communication. Concepts under the heading of variables and causal relationships are represented as the relationships among variables. If there is a direct (i.e., positive) relationship between the two variables, an increase or decrease in the cause variable will cause a change in the same direction (increase or decrease) in the disabled variable. If the relationship is inverse (i.e., negative), the change caused by the cause variable is applied in the opposite direction to the effect variable. Therefore, considering the 
quality of perceptual mapping and, on the other hand, considering the quantification power of fuzzy logic, Kosko (1986) introduced fuzzy cognitive mapping with fuzzy weights.

According to Kosko's (1986) definition, FCM is a graphical guided graph showing cause-andeffect relationships among factors. A number in the range [-1 to 1] determines the relationship between each factor pair in this model. The FCM model represents both quantitative and qualitative data (see Rodrigues, 2007). Creating an FCM model requires inputs that draw on the experience and knowledge of experts in the field. Thus, in FCM models, the accumulated experiences of individuals or existing knowledge in the area for which the model is drawn are integrated and based on them, cause and effect relationships are formed between the components of the system (see Alizadeh \& Hooshmand, 2007). One of the methods of making FCM is the shortest distance. Learning methods have also been widely used to teach FCM. FCM learning is accomplished by fine-tuning the initial causal relationships or weight strength of FCMs with the help of artificial neural network learning algorithms or meta-heuristic algorithms. The value of using FCM is well understood when managers can test their strategic changes and see the results of changes in model concepts. Simulation and analysis of fuzzy cognitive mapping and design of different scenarios allow managers and experts to answer questions such as 'what are the different ways to achieve a specific goal?', 'What are the most important and key factors of concepts in achieving goals?', and 'Which way to achieve the goals has the highest level of belief in feasibility among experts?' (Axelrod, 1976).

Step 1: Determining the existing factors and solutions to the problem: First, the solutions (i.e., factors) for overcoming the coronavirus crisis are identified using experts' opinions and are presented in the (see Table 6).

Table 6: Strategies for Overcoming the Coronavirus Crisis

\begin{tabular}{|l|l|}
\hline Number & Solutions \\
\hline F1 & Stimulating the sense of responsibility in the tourist to maintain the health of themselves and others \\
\hline F2 & Providing a plan to adapt the market and simulate products to the demand of tourists \\
\hline F3 & $\begin{array}{l}\text { Maintaining and communicating with previous and loyal customers as starting points (i.e., travel } \\
\text { initiator) }\end{array}$ \\
\hline F4 & Setting up small but professional teams \\
\hline F5 & The need to take crisis management knowledge and business resilience seriously in business \\
\hline F6 & $\begin{array}{l}\text { Exemption of business taxes and energy bills for tourism industry activists and paying subsidies } \\
\text { and being supported by the government }\end{array}$ \\
\hline F7 & $\begin{array}{l}\text { The low price of the country's currency is an opportunity to plan to get foreign tourists' attraction } \\
\text { in accordance with health protocols. }\end{array}$ \\
\hline F8 & Presenting an action plan in the target countries \\
\hline F9 & Recognising the behaviour and desires of businesses \\
\hline F10 & Collecting and summarising information at the regional and local level \\
\hline F11 & $\begin{array}{l}\text { Implementing of the target market determination plan at the international level and identification } \\
\text { of target countries and cities (with the white flag, i.e., less infected with coronavirus) }\end{array}$ \\
\hline F12 & Presenting an action plan to build trust in the safety and security of tourists in the country \\
\hline F13 & Forming a crisis management team \\
\hline F14 & The control of fixed and overhead costs for organisational agility \\
\hline F15 & Due to the high risk of tourism, finding a safe area in related and unrelated areas. \\
\hline
\end{tabular}

Step 2: Determining the prevailing relationships among factors is done by comparing them in pairs, and then on the next step

Step 3: Determining the pairwise comparison matrix becomes a fuzzy spectrum; and then

Step 4: Forming a diffuse decision matrix and more on

Step 5: Forming the final decision matrix, and in this step, the final decision matrix obtained from experts' opinions enters the FCMapper software. This software determines weights and cause-and-effect relationships, then 
Step 6: Pajek software draws a fuzzy cognitive map using the output of FCMapper software. In the fuzzy cognitive map, the solutions to the coronavirus crisis can be seen in Figure 1. According to the information shown in Figure 1, this map has 15 knots and 205 arcs. Nodes represent the way out of the coronavirus crisis, and arcs represent the relationships among nodes. In this map, the relationships among factors are direct and two-way (See Figure. 1).

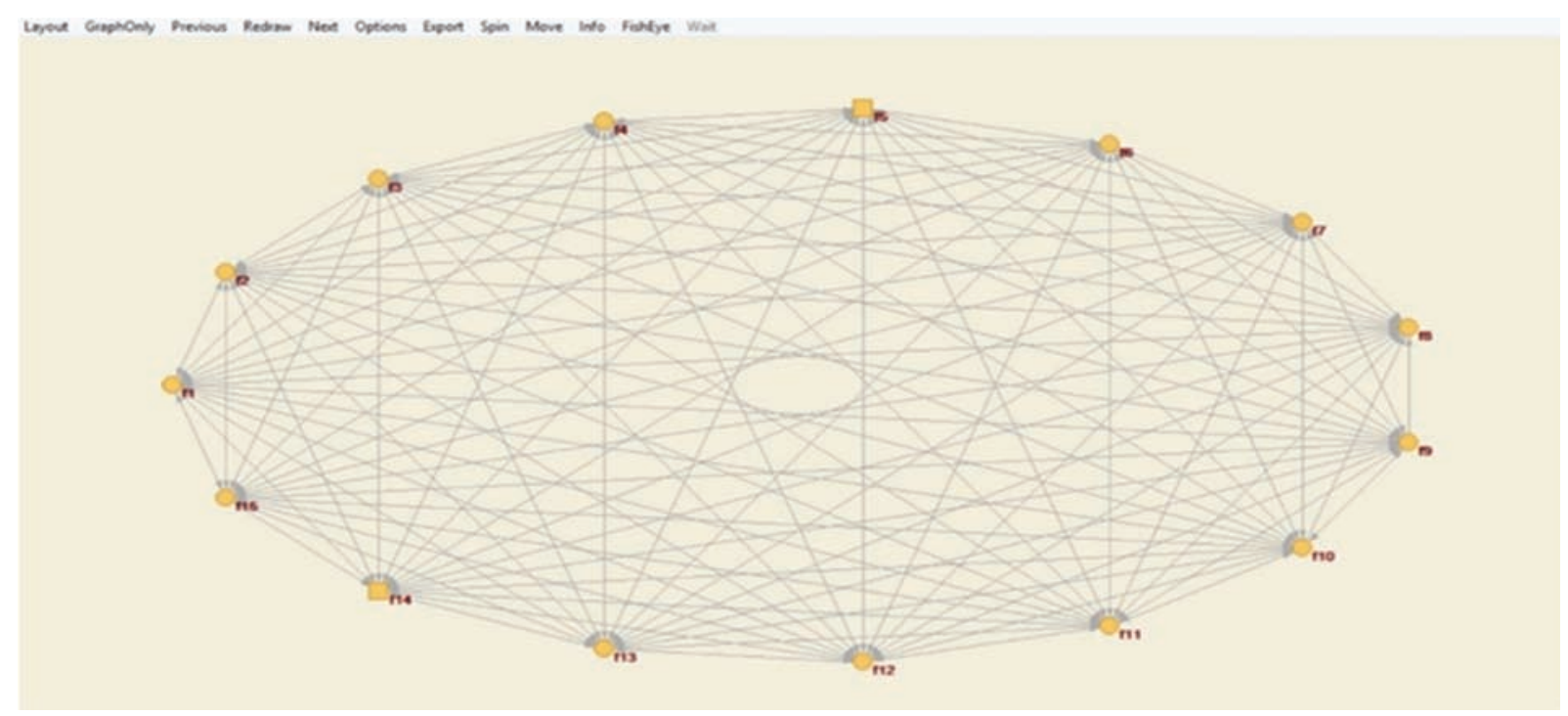

Figure 1: Fuzzy Cognitive Map

As for the first research question, i.e., identifying the most important challenges of the tourism industry to obtain the answers to the research questions, a questionnaire was prepared to assess the COVID-19 era. The challenges were created to review and identify the leading opportunities in the tourism industry of Iran, and in a semi-structured interview with experts, questions were asked. Distinguished experts from the academic community, experts from the Ministry of Cultural Heritage and Tourism, and industry representatives. Table 7 lists some of the coronavirus outbreak harms to international tourism announced by the World Travel and Tourism Organization.

Table 7: The Pathology of the Crisis Caused by the Outbreak of the COVID-19 in World Tourism

\begin{tabular}{|c|c|}
\hline Number & Pathology of the Crisis Caused by the Outbreak of the COVID-19 on World Tourism \\
\hline 1 & Travel restrictions from April 6 2020, in 96\% of destinations worldwide \\
\hline 2 & UNWTO anticipation about 20-30\% reduction in international travels by 2020 \\
\hline 3 & $\begin{array}{l}\text { 1.2billion reductions in international air travel, IATA predicts \$ } 252 \text { billion in airline revenue cuts } \\
\text { and } 5 \text { million job losses this year }\end{array}$ \\
\hline 4 & $\begin{array}{l}12000 \text { British Airways employees laid off and } € 535 \text { million financial loss during Corona to the } \\
\text { company in the first quarter of } 2020\end{array}$ \\
\hline 5 & Financial loss equivalent to one million euros per hour for Lufthansa \\
\hline 6 & 10\% expulsion of Boeing employees \\
\hline 7 & $\begin{array}{l}\text { Predict the loss of one million jobs every day and unemployment of one hundred million people in } \\
\text { the travel and tourism sector in the world }\end{array}$ \\
\hline 8 & $\begin{array}{l}\text { Asia-Pacific region one of the most affected regions in the world, with more than } 63 \text { million job } \\
\text { losses }\end{array}$ \\
\hline 9 & Cancellation or postponement of events such as the Berlin Tourism Fair, the Olympic Games \\
\hline 10 & $\begin{array}{l}\text { Hotel employment decline of } 96 \% \text { in Italy, } 68 \% \text { in China, } 67 \% \text { in the UK, } 59 \% \text { in the United States } \\
\text { and } 48 \% \text { in Singapore compared to } 2019\end{array}$ \\
\hline 11 & 70\% expulsion of American hotels employees \\
\hline 12 & Firing one out of five employees in German travel agencies \\
\hline
\end{tabular}

References: (WTTC, April 28 2020, Hotel News Group, April and May 2020) 
Table 8 shows the results of solutions to overcome the coronavirus crisis based on the level of implementation, degree, and concentration of the FCM model.

Table 8: Out-degree, In-degree, and Centrality of Concepts

\begin{tabular}{|l|l|l|l|l|l|c|}
\hline Concepts & Out degree & In degree & Centrality & Transmitter & Receiver & Ordinary \\
\hline F1 & 6.50 & 4.25 & 10.75 & & & 1 \\
\hline F2 & 8.50 & 8.25 & 16.75 & & & 1 \\
\hline F3 & 5.00 & 7.50 & 12.50 & & & 1 \\
\hline F4 & 7.75 & 8.50 & 16.25 & & & 1 \\
\hline F5 & 9.25 & 8.75 & 18.00 & & & 1 \\
\hline F6 & 8.99 & 9.25 & 18.24 & & & 1 \\
\hline F7 & 5.50 & 8.00 & 13.50 & & & 1 \\
\hline F8 & 5.75 & 9.00 & 14.75 & & & 1 \\
\hline F9 & 6.00 & 6.00 & 12.00 & & & 1 \\
\hline F10 & 9.50 & 7.00 & 16.50 & & & 1 \\
\hline F11 & 8.25 & 8.75 & 17.00 & & & 1 \\
\hline F12 & 8.50 & 10.25 & 18.75 & & & 1 \\
\hline F13 & 10.25 & 7.00 & 17.25 & & & 1 \\
\hline F14 & 7.25 & 9.99 & 15.24 & & & 1 \\
\hline F15 & 9.50 & 6.00 & 15.50 & & & 1 \\
\hline
\end{tabular}

According to the information provided in Table 7 and Table 8, out-degree, in-degree, and centrality of concepts have been shown based on the fifteen factors.

Step 7: scenario building (data analysis): In scenario building, we should pay attention to the scenario in which we can change the factors that have the most significant impact on solutions to exit the coronavirus crisis, given the close connection between exit solutions. Coronavirus crisis weakens or strengthens one factor, directly affecting other factors. The first scenario was set based on Figure 2.

\begin{tabular}{|c|c|c|c|c|c|c|c|c|c|c|}
\hline $\begin{array}{l}\text { Domesti } \\
\text { c } \\
\text { Tourism }\end{array}$ & & & & & & & & & & \\
\hline $\begin{array}{l}\text { Select } \\
\text { Scene }\end{array}$ & 3 & \multirow{2}{*}{\multicolumn{2}{|c|}{$\begin{array}{l}\text { Calculate Selected } \\
\text { Scenario }\end{array}$}} & \multirow{2}{*}{\multicolumn{2}{|c|}{ Compare Scenarios }} & & & & & $\begin{array}{c}\% \text { of } \\
\text { Variable } \\
\text { s } \\
\text { changed }\end{array}$ \\
\hline $\begin{array}{l}\text { Number } \\
\text { of } \\
\text { Iteration } \\
\mathrm{s}\end{array}$ & 15 & & & & & & & & & $\begin{array}{c}\text { Scenario } \\
3\end{array}$ \\
\hline $\begin{array}{c}\text { Concept } \\
\text { s }\end{array}$ & $\begin{array}{l}\text { No } \\
\text { Chang } \\
\text { es } \\
\text { (Scene } \\
1 \text { ) }\end{array}$ & Scene 3 & $\begin{array}{l}\text { Results- } \\
\text { No } \\
\text { Changes } \\
\text { (Scene } \\
1 \text { ) }\end{array}$ & $\begin{array}{l}\text { Results- } \\
\text { No } \\
\text { Changes } \\
\text { (Scene } \\
\text { 3) }\end{array}$ & $\begin{array}{l}\text { Scenario 3- } \\
\text { Scenario } 1\end{array}$ & & $\begin{array}{c}\text { Positive } \\
\text { Change } \\
\text { s }\end{array}$ & $\begin{array}{l}\text { Strengt } \\
\mathrm{h} \text { (pos.) }\end{array}$ & $\begin{array}{l}\text { Negativ } \\
\text { e } \\
\text { Changes }\end{array}$ & $\begin{array}{l}\text { Strength } \\
\text { (neg.) }\end{array}$ \\
\hline f1 & 1.00 & & 0.99 & $\begin{array}{c}0.98591 \\
5\end{array}$ & $\begin{array}{c}0.0000243 \\
0\end{array}$ & 1 & $\mathrm{~F} 1$ & 4 & & \\
\hline $\mathrm{f} 2$ & 1.00 & & $\begin{array}{c}0.99973 \\
5\end{array}$ & $\begin{array}{c}0.99973 \\
6\end{array}$ & $\begin{array}{c}0.0000007 \\
0\end{array}$ & 1 & F2 & 4 & & \\
\hline f3 & 1.00 & & $\begin{array}{c}0.99944 \\
1\end{array}$ & $\begin{array}{c}0.99944 \\
2\end{array}$ & $\begin{array}{c}0.0000008 \\
9\end{array}$ & 5 & f3 & 4 & & \\
\hline $\mathrm{f} 4$ & 1.00 & & $\begin{array}{c}0.99979 \\
4\end{array}$ & $\begin{array}{c}0.99979 \\
5\end{array}$ & $\begin{array}{c}0.0000005 \\
5\end{array}$ & 5 & $\mathrm{~F} 4$ & 4 & & \\
\hline f5 & 1.00 & & 0.99984 & 0.99984 & $\begin{array}{c}0.0000004 \\
3\end{array}$ & 5 & F5 & 4 & & \\
\hline
\end{tabular}




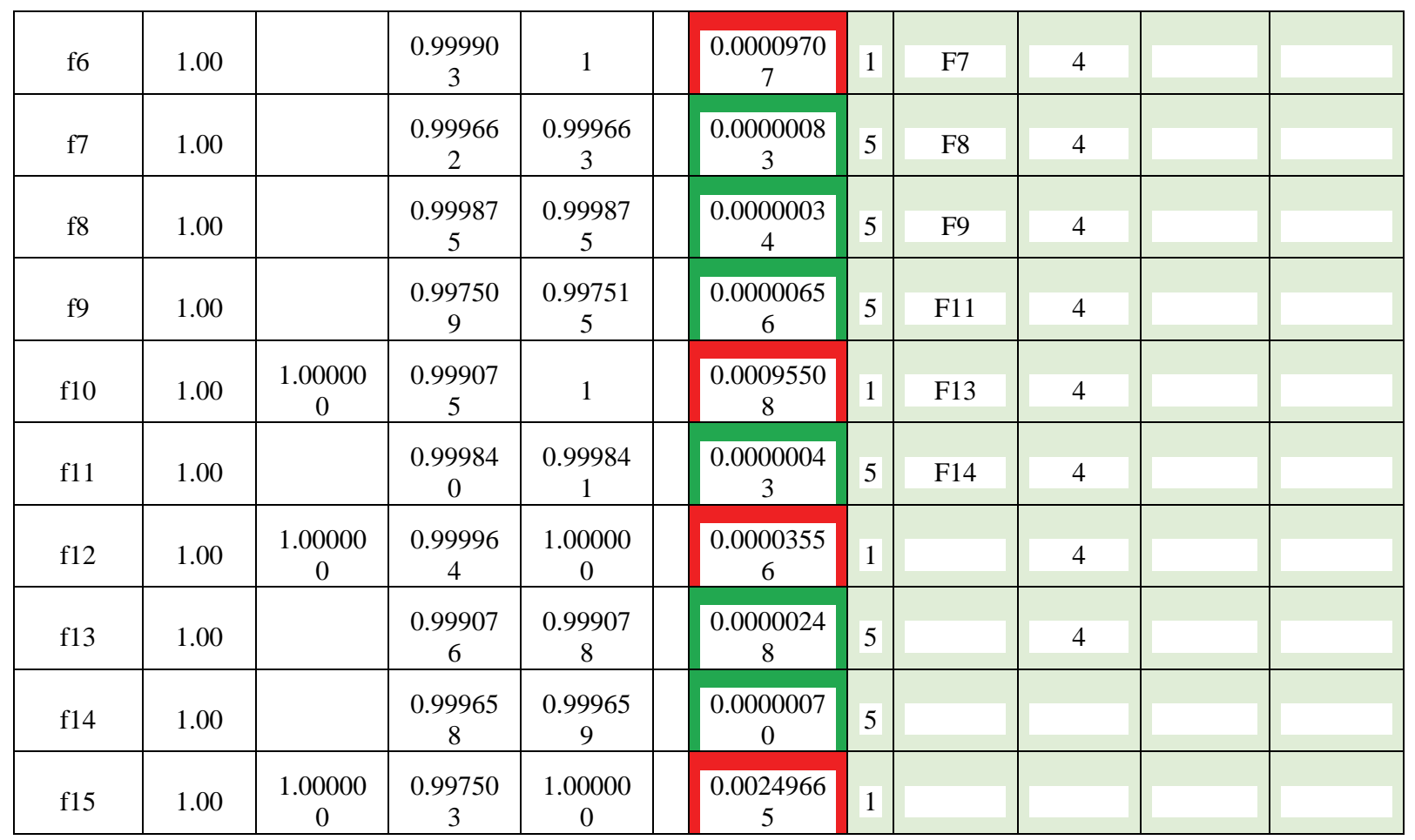

Figure 2: Review of Priority Factors (Step 1)

Table 9: Prioritisation of Solutions to Exit the Coronavirus Crisis Based on the Degree of Centrality

\begin{tabular}{|l|l|}
\hline Number & Factors \\
\hline 1 & Presenting an action plan to build trust for the safety and security of tourists in the country (F12) \\
\hline 3 & $\begin{array}{l}\text { Exemption of business taxes and energy bills for tourism industry activists and paying subsidies } \\
\text { and being supported by the government (F6) }\end{array}$ \\
\hline 4 & The need to take crisis management knowledge and business resilience seriously in business (F5) \\
\hline 5 & $\begin{array}{l}\text { Implementing the target market determination plan at the international level and identification of } \\
\text { target countries and cities (with the white flag, i.e., less infected with coronavirus) (F11) }\end{array}$ \\
\hline 6 & Provide a plan to adapt the market and simulate products to the demand of tourists (F2) \\
\hline 7 & Collecting and summarising information at the regional and local level (F10) \\
\hline 8 & Setting up small but professional teams (F4) \\
\hline 9 & Due to the high risk of tourism, finding a safe area in related and unrelated areas (F15) \\
\hline 10 & Control of fixed and overhead costs for organisational agility (F14) \\
\hline 11 & Present an action plan in the target countries (F8) \\
\hline 12 & $\begin{array}{l}\text { The low price of the country's currency is an opportunity to plan to get foreign tourists' attraction } \\
\text { in accordance with health protocols (F7) }\end{array}$ \\
\hline 13 & $\begin{array}{l}\text { Maintaining and communicating with previous and loyal customers as starting points (i.e., travel } \\
\text { initiator) (F3) }\end{array}$ \\
\hline 14 & Recognise the behaviour and desires of businesses (F9) \\
\hline 15 & $\begin{array}{l}\text { Stimulate the sense of responsibility in the tourist to maintain the health of themselves and others } \\
\text { (F1) }\end{array}$ \\
\hline
\end{tabular}

Scenario 1: first, presenting an action plan to build trust for the safety and security of tourists in the country (F12) and exemption of business taxes and energy bills for tourism industry activists (F6), and paying subsidies and being supported by the government, were the first and second priorities. Collecting and summarising information at the regional and local level (F10), and due to the high risk of tourism, finding a safe area in related and unrelated areas (F15) is considered as a low priority (i.e., sub-priority) extracted from FCmapper software and to scenario, those four factors were strengthened. The result of this scenario had a positive effect on all other factors and increased them. 
Scenario 2: In this scenario, we consider the factor of providing a plan to adapt the market and simulate products to the demand of tourists (F2) as a priority factor and stimulating the tourist's sense of responsibility to maintain their health and the health of others as a low priority factor (i.e., sub-priority) that increased other factors. The second scenario was adjusted based on Figure 3.

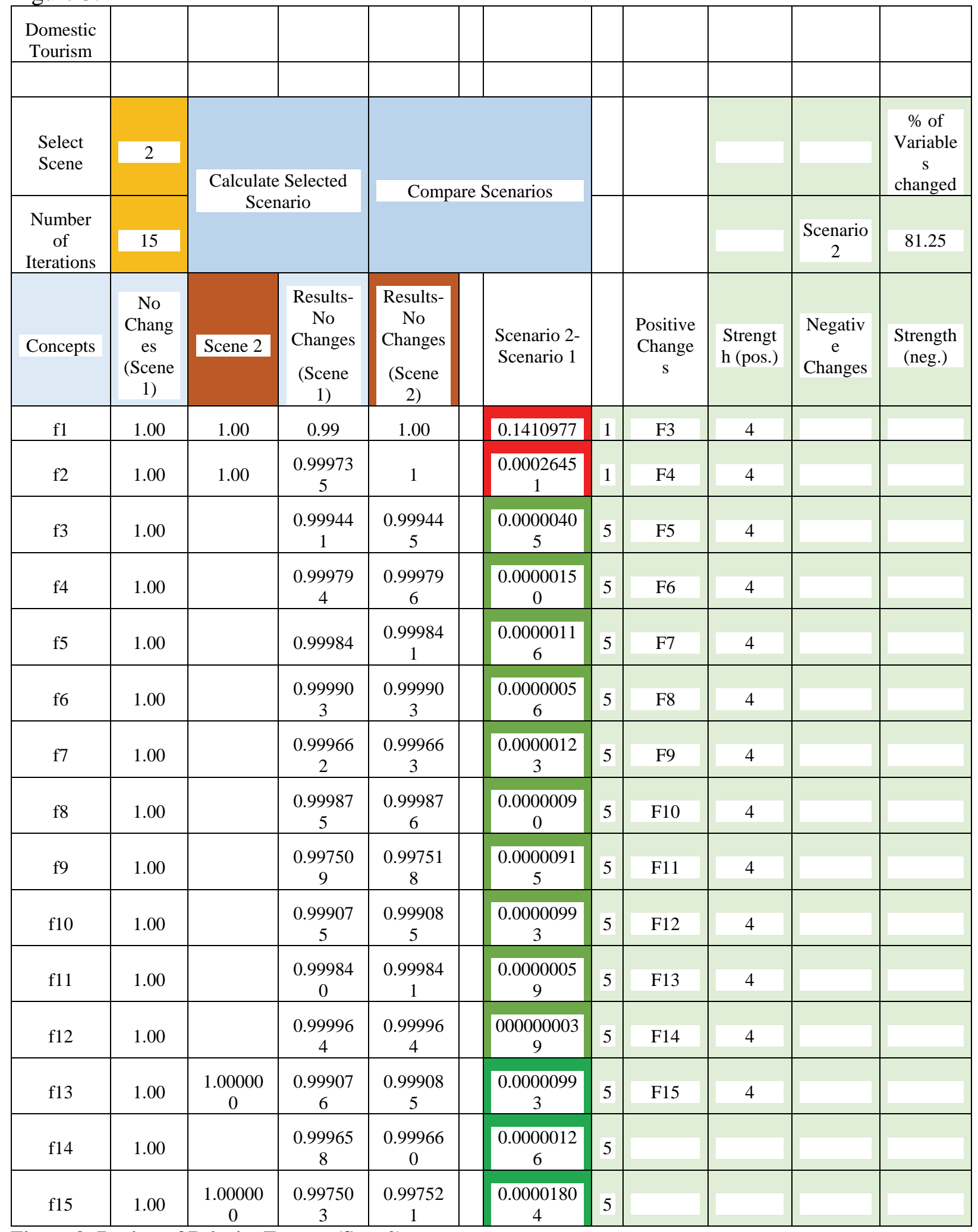

Figure 3: Review of Priority Factors (Step 2) 
Scenario 3: The formation of a crisis management team (F13) was considered and strengthened as a priority factor, and the factor of finding a safe zone in related and unrelated areas (F15) was a low priority (sub) factor in the third scenario. The results of this scenario showed an increase in other ways out of the coronavirus crisis. Therefore, the third scenario was set based on the priority factors (see, Figure 4).

\begin{tabular}{|c|c|c|c|c|c|c|c|c|c|c|}
\hline $\begin{array}{c}\text { Domestic } \\
\text { Tourism }\end{array}$ & & & & & & & & & & \\
\hline $\begin{array}{l}\text { Select } \\
\text { Scene }\end{array}$ & 3 & \multirow{2}{*}{\multicolumn{2}{|c|}{$\begin{array}{l}\text { Calculate Selected } \\
\text { Scenario }\end{array}$}} & \multirow{2}{*}{\multicolumn{2}{|c|}{ Compare Scenarios }} & & & & & $\begin{array}{c}\% \text { of } \\
\text { Variable } \\
\text { s } \\
\text { changed }\end{array}$ \\
\hline $\begin{array}{c}\text { Number } \\
\text { of } \\
\text { Iterations }\end{array}$ & 15 & & & & & & & & $\begin{array}{c}\text { Scenario } \\
3\end{array}$ & 81.25 \\
\hline Concepts & $\begin{array}{l}\text { No } \\
\text { Chang } \\
\text { es } \\
\text { (Scene } \\
1 \text { ) }\end{array}$ & Scene 3 & $\begin{array}{c}\text { Results- } \\
\text { No } \\
\text { Changes } \\
\text { (Scene } \\
1 \text { ) }\end{array}$ & $\begin{array}{l}\text { Results- } \\
\text { No } \\
\text { Changes } \\
\text { (Scene } \\
\text { 3) }\end{array}$ & $\begin{array}{l}\text { Scenario 3- } \\
\text { Scenario } 1\end{array}$ & & $\begin{array}{c}\text { Positive } \\
\text { Change } \\
\text { s }\end{array}$ & $\begin{array}{l}\text { Strengt } \\
\mathrm{h} \text { (pos.) }\end{array}$ & $\begin{array}{c}\text { Negativ } \\
\text { e } \\
\text { Changes }\end{array}$ & $\begin{array}{c}\text { Strength } \\
\text { (neg.) }\end{array}$ \\
\hline f1 & 1.00 & & 0.99 & $\begin{array}{c}0.98591 \\
4\end{array}$ & $\begin{array}{c}0.0000238 \\
3\end{array}$ & 5 & f1 & 4 & & \\
\hline $\mathrm{f} 2$ & 1.00 & & $\begin{array}{c}0.99973 \\
5\end{array}$ & $\begin{array}{c}0.99973 \\
6\end{array}$ & $\begin{array}{c}0.0000006 \\
8\end{array}$ & 5 & $\mathrm{f} 2$ & 4 & & \\
\hline $\mathrm{f} 3$ & 1.00 & & $\begin{array}{c}0.99944 \\
1\end{array}$ & $\begin{array}{c}0.99944 \\
2 \\
\end{array}$ & $\begin{array}{c}0.0000010 \\
9\end{array}$ & 5 & f3 & 4 & & \\
\hline $\mathrm{f} 4$ & 1.00 & & $\begin{array}{c}0.99979 \\
4\end{array}$ & $\begin{array}{c}0.99979 \\
5\end{array}$ & $\begin{array}{c}0.0000005 \\
3\end{array}$ & 5 & $\mathrm{f} 4$ & 4 & & \\
\hline f5 & 1.00 & & 0.99984 & 0.99984 & $\begin{array}{c}0.0000004 \\
1\end{array}$ & 5 & f5 & 4 & & \\
\hline f6 & 1.00 & & $\begin{array}{c}0.99990 \\
3\end{array}$ & $\begin{array}{c}0.99990 \\
3\end{array}$ & $\begin{array}{c}0.0000002 \\
5\end{array}$ & 5 & f6 & 4 & & \\
\hline f7 & 1.00 & & $\begin{array}{c}0.99966 \\
2\end{array}$ & $\begin{array}{c}0.99966 \\
3\end{array}$ & $\begin{array}{c}0.0000008 \\
7\end{array}$ & 5 & f7 & 4 & & \\
\hline f8 & 1.00 & & $\begin{array}{c}0.99987 \\
5\end{array}$ & $\begin{array}{c}0.99987 \\
5\end{array}$ & $\begin{array}{c}0.0000003 \\
2\end{array}$ & 5 & f8 & 4 & & \\
\hline f9 & 1.00 & & $\begin{array}{c}0.99750 \\
9 \\
\end{array}$ & $\begin{array}{c}0.99751 \\
5 \\
\end{array}$ & $\begin{array}{c}0.0000003 \\
9\end{array}$ & 5 & f9 & 4 & & \\
\hline $\mathrm{f} 10$ & 1.00 & & $\begin{array}{c}0.99907 \\
5\end{array}$ & $\begin{array}{c}0.99907 \\
7\end{array}$ & $\begin{array}{c}0.0000018 \\
2\end{array}$ & 5 & $\mathrm{f} 10$ & 4 & & \\
\hline $\mathrm{f} 11$ & 1.00 & & $\begin{array}{c}0.99984 \\
0 \\
\end{array}$ & $\begin{array}{c}0.99984 \\
1 \\
\end{array}$ & $\begin{array}{c}0.0000004 \\
1\end{array}$ & 5 & $\mathrm{f} 11$ & 4 & & \\
\hline $\mathrm{f} 12$ & 1.00 & & $\begin{array}{c}0.99996 \\
4\end{array}$ & $\begin{array}{c}0.99996 \\
4\end{array}$ & $\begin{array}{c}0.0000001 \\
0\end{array}$ & 5 & $\mathrm{f} 12$ & 4 & & \\
\hline $\mathrm{f} 13$ & 1.00 & $\begin{array}{c}1.00000 \\
0 \\
\end{array}$ & $\begin{array}{c}0.99907 \\
6 \\
\end{array}$ & $\begin{array}{c}1.00000 \\
0 \\
\end{array}$ & $\begin{array}{c}0.0000144 \\
8\end{array}$ & 1 & f14 & 4 & & \\
\hline f14 & 1.00 & & $\begin{array}{c}0.99965 \\
8\end{array}$ & $\begin{array}{c}0.99965 \\
9\end{array}$ & $\begin{array}{c}0.0000006 \\
7\end{array}$ & 5 & & & & \\
\hline f15 & 1.00 & $\begin{array}{c}1.00000 \\
0 \\
\end{array}$ & $\begin{array}{c}0.99750 \\
3 \\
\end{array}$ & $\begin{array}{c}1.00000 \\
0 \\
\end{array}$ & $\begin{array}{c}0.0024944 \\
5\end{array}$ & 1 & & & & \\
\hline
\end{tabular}

Figure 4: Review of Priority Factors (Step 3) 


\section{Conclusion, Implications, and Suggestions}

On the one hand, the widespread of the disease worldwide and its vast impact on economic, social, environmental, and political issues have led to governments' intervention and support. In addition, the control of the disease epidemic is not possible except at the macro level. On the other hand, due to the strong dependence of the tourism industry on the national macro-policies, these two issues cannot be considered separately, and tourism is undoubtedly intertwined in the country's macro policies. Answering the first question of the research according to the results of interviews and research documents, paying staffs salaries, paying bank instalments, rent, bills, taxes, paying staff insurance premiums, refund of cancelled travel funds, the impossibility of refunding paid funds for booking foreign payments and hotels, trained manpower layoffs, hotel upkeeps costs at the time of hotel closure, health and safety of staff and tourists matter, long epidemic and intolerance of travellers, widespread consequences of this event (epidemic), fear of the future, and lack of necessary liquidity of travel services offices to compensate Travel cancellation (tickets, hotels, etc.) were the most critical challenges in tourism industries. In addition, the lack of laws to compensate costs, the departure of service offices from the normal situation and rising unemployment in the country as a result of closure of tourism activities, lack of government funding to support affected businesses, lack of efficient risk management system, conflict resolution management among tourism stakeholders, ensuring the health and safety of travelers and setting health protocols for tourism facilities, training of tourism sector personnel, lack of tourism industry support fund, concerns of political and social tensions following deepening economic challenge, coronary crisis typology, pressure Psychology on the people, responsibility to the people and the private sector, lack of vision and clear vision of the future, lack of clear regulations in the country and lack of transparency in the crisis, the challenge of socio-cultural development and happiness of families in crisis were the most important challenges of the public tourism sector are:.

The answer to the second question was based on identifying the leading opportunities in the tourism industry and the public sector. Transformation of traditional tourism model into a new model based on tourists' needs and sustainability of services and goods in critical situations, increasing digital marketing and communication with domestic and foreign audience to build safe and risk-free travel, maintaining and communicating with previous and loyal customers as starting points, opportunity for small businesses by controlling and reducing costs and flexibility to change strategies, creating parallel and complementary businesses to minimise vulnerability in crisis, providing accurate statistics to assess the situation at the regional and local level, the opportunity to participate tourism and the health sector of the country, the low price of the Iran currency is an opportunity to plan getting foreign tourists' attraction in accordance with health protocols, interacting with tourism associations and veterans by forming a think tank and exchanging views and pursuing trade union rights, the opportunity to stimulate a tourist's sense of commitment and responsibility to maintain their health and the health of others, recognising the behavior and desires of businesses were opportunities ahead. In the last part, using the opinion of experts and reviewing global experiences, the analysis of ways out of the corona crisis is presented.

The most important ways out of the corona crisis are:

Action plan for building trust, tax forgiveness, and payment of government subsidies and support, the need to take crisis management knowledge seriously and form a crisis management tea, plan to determine the target market, and plan of action at national and international level was the result. Using the results of scenario building and implementing the first priority, i.e., the action plan of trust-building advertisements, it is possible to increase digital marketing and communication with domestic and foreign audiences to build a safe and risk-free trip in Iran by 
observing health protocols. To implement the second priority, tax exemption and payment of government subsidies and subsidies, information can be collected and summarised at the regional and local level.

To implement the third and fourth priorities, i.e., the need to take crisis management knowledge seriously and form a management team, it is possible to set up small specialised and professional teams and find a safe area in related and unrelated areas. Furthermore, to implement the fifth priority, i.e., the plan to determine the target market and the plan of action at the domestic and international level, it is possible to maintain and communicate with previous and loyal customers as starting points (i.e., travel initiators), it also focused on identifying target countries (with white flags, i.e., less infected with coronavirus), as well as identifying cities with white flags in designated countries. Finally, to implement the fifth priority, the plan was to adapt the market and simulate products to the demand of tourists and control costs to improve organisational agility.

Due to the legal constraints created by the Coronavirus outbreak crisis, the most significant restrictions were the prohibition on face-to-face communication and the lack of library information due to the global scale of the crisis and the lack of global crisis experience, bound the researchers to conduct online interviews and gathering information from authentic, updated resources of the world.

Due to the extent and duration of this epidemic crisis, it is necessary to involve all stakeholders involved in the crisis in further pieces of research. For example, investigating how to authorise the private sectors of the tourism industry, how to further cooperate with the pillars of the tourism industry, and how to establish a partnership with the public sectors can be some suggestions for doing further research.

Since the International Journal of Management, Knowledge and Learning (IJMKL) aims to bring together the researchers and practitioners in business and education to provide advanced knowledge for modern life, the present paper seems relevant to the scope and aim of the journal. It may have some theoretical and practical implications.

\section{References}

Alizadeh, S., \& Hooshmand, S. (2007). Learning FCM by tabu search. International Journal of Computer Science, 2(2), 142-149.

Alzoubi, R. H. M., \& Jaaffar, A. H. (2020). Leadership styles, crisis management, and hotel performance: a conceptual perspective of the Jordanian hotel industry, Journal of Critical Reviews, 7, 10, and 2020. Retrieved from https://www.researchgate.net/profile/raed_alzoubi/publication/342855920_leadersh ip_styles_crisis_management and hotel_performance_a_conceptual_perspective_of the_jordanian_hotel/links/5f0dadbc4585158917b f3022/leadership-styles-crisis-management-and-hotel-performance-a-conceptual-perspective-of-thejordanian-hotel.pdf

Armstrong, M. (2020). Coronavirus crisis sparks race for inventive solutions. Retrieved from www.euronews.com/2020/03/21/coronavirus-crisis-sparks-race-for-inventive-solutions, Accessed April 192020.

Axelrod, R. (1976). Structure of decision. The cognitive maps of political elites. New Jersey, Princeton University Press.

Bulletin Number 8. (2020). Ministry of Cultural Heritage, Tourism, and Handicrafts. Retrieved from https://t.me/boltanbazaryabi/87.

Bundy, J., \& Pfarrer, M. D. (2015). A burden of responsibility: The role of social approval at the onset of a crisis. Academy of Management Review, 40: 345-369.

Coombs, W. T. (2007). Protecting organisation reputations during a crisis: The development and application of situational crisis communication theory. Corporate Reputation Review, 10: 163-176.

Daft, R. (1983). Learning the craft of organisational research. Academy of management review, 8, 539-541.

Davahli, M., Karwowski, W., Sonmez, S. \& Apostolopoulos, Y. (2020). The Hospitality Industry in the Face of the COVID-19 Pandemic: Current Topics and Research Methods, International Journal of Environment Research and Public Health. Retrieved from https://www.mdpi.com/1660-4601/17/20/7366/pdf 
Frisby, E. (2003). Communicating in a crisis: The British tourist Authority's responses to the foot-and-mouth outbreak and September 11 2001. Journal of Vacation Marketing, 9(1), 89-100. Retrieved from https://doi.org/10.1177/135676670200900107.

Goletsa, A., Fariasb, J., Pilatib, R. \& Costac, H. (2020). COVID-19 pandemic and tourism: The impact of health risk perception and intolerance of uncertainty on travel intentions. Retrieved from https://www.preprints.org/manuscript/202010.0432/v1/download.

Gössling, S.; Scott, D. \& Hall, C. M. (2020). Pandemics, tourism, and global change: a rapid assessment of COVID-19. Journal of Sustainable Tourism, 1-20. Retrieved from https://www.tandfonline.com/doi/full/10.1080/09669582.2020.1758708

He, H. \& Harris, L. (2020). The impact of COVID-19 pandemic on corporate social responsibility and marketing philosophy. Journal of Business Research, 116: 176-182. Retrieved from https://www.sciencedirect.com/science/article/pii/S0148296320303295.

Hunziker, W. (1951). Le Tourisme. Berne.

Jiang, Y., \& Wen, J. (2020). Effects of COVID-19 on hotel marketing and management: a perspective article. International Journal of Contemporary Hospitality Management. Retrieved from https://www.researchgate.net/publication/341611962_Effects_of_COVID-

19_on_hotel_marketing_and_management_A_perspective_article.

Jose, L. S. (2009). Augmented fuzzy cognitive maps for Modelling LMS critical success factors. Knowl Based Syst. 22(40):275-8.

Kosko, B. (1986). Fuzzy cognitive maps. Int J Manage Stud. 24(1):65-75.

Kvale, S. (1996). Interviews: an introduction to qualitative research interviewing. Thousand Oaks, Calif: Sage Publications. Maso.

Lai, I. K. W., \& Wong, J. W. C. (2020). Comparing crisis management practices in the hotel industry between initial and pandemic stages of COVID-19. International Journal of Contemporary Hospitality Management. Retrieved from https://www.emerald.com/insight/content/doi/10.1108/IJCHM-04-20200325/full/html?skipTracking=true

Last, J. M. A dictionary of epidemiology (Second Edition). Oxford: Oxford University Press, 1988.

Madani, A.; Boutebal, S.E.; Benhamida, H.; Bryant, C.R. The Impact of Covid-19 Outbreak on the Tourism Needs of the Algerian Population. Sustainability, 12, 8856. Available at: https://www.preprints.org/manuscript/202009.0633/v1.

Mason, P., Grabowski, P., \& Du, W. (2005). Severe acute respiratory syndrome, tourism and the media. International Journal of Tourism Research, 7(1), 11-21. https://doi.org/10.1002/jtr.519

Morakabati, Yeganeh, P., Stephen J., \& Fletcher, J. (2017) Emergency Management and Tourism Stakeholder Responses to Crises: A Global Survey, Journal of Travel Research, 56(3) 299-316

Morens, D. M., Folkers, G. K. \& Fauci, A. S. (2009). What Is a Pandemic? The Journal of Infectious Diseases, 200: 1018-21. Retrieved from https://academic.oup.com/jid/article/200/7/1018/903237

Novelli, M., Gussing-Burgess, L., Jones, A., \& Ritchie, B. W. (2018). No Ebola...still doomed - The Ebolainduced tourism crisis. Annals of Tourism Research, 70, 76-87. Retrieved from https://doi.org/10.1016/j.annals.2018.03.006.

Ritchie, B. W.; Jiang, Y. A review of research on tourism risk, crisis, and disaster management: Launching the annals of tourism research curated collection on tourism risk, crisis, and disaster management. Ann. of Tour. Res., 79, 102812.

The World Bank. (2020). International tourism, expenditures (current US\$). https://data.worldbank.org/indicator/ST.INT.XPND.CD?end=2018\&most_recent_value_desc $=$ false\&start $=2018 \&$ view $=$ map \&year $=2017$.

WHO \& UNWTO. (2020, February 27). A joint statement on tourism and COVID-19 - UNWTO and WHO call for responsibility and coordination. World Health Organization. Retrieved from https://www.who.int/news-room/detail/27-02-2020-a-joint-statementon-tourism-and-covid-19—unwtoand-who-call-for-responsibility-and-coordination.

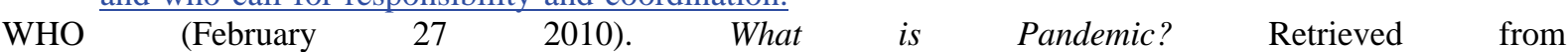
https://www.who.int/csr/disease/swineflu/frequently_asked_questions/pandemic/en/

Yeh, S. S. (2020). Tourism recovery strategy against COVID-19 pandemic. Tourism Recreation Research, 1: 1-7. Retrieved from https://www.tandfonline.com/doi/full/10.1080/02508281.2020.1805933

Yeoman, I.; Robertson, M.; McMahon-Beattie, U.; Smith, K.; Backer, E. (Eds.) (2014). The future of events and festivals. Routledge: Abingdon.

Zeng, B., Carter, R. W., \& De-Lacy, T. (2005). «Short-term perturbations and tourism effects: The case of SARS in China». Current Issues in Tourism, 8(4), 306-322. Retrieved from https://doi.org/10.1080/13683500508668220 
Zielinski, S., \& Botero, C. M. (2020). Beach Tourism in Times of COVID-19 Pandemic: Critical Issues, Knowledge Gaps, and Research Opportunities. International Journal of Environmental Research and Public Health, 17(19), 7288. Retrieved from https:/www.ncbi.nlm.nih.gov/pmc/articles/PMC7579372/. 